\title{
Gamma Irradiation Effects on Track Properties of PADC-American Acrylics Track Detector
}

\author{
DIPAK SINHA \\ Department of Chemistry, Nagaland University, Lumami Campus \\ Nagaland-798627, India \\ dipaksinha@gmail.com
}

Received 11 October 2011; Accepted 30 December 2011

\begin{abstract}
Gamma irradiation effects on track properties of Polyallyl Diglycol Carbonate (PADC) track detector (PADC-American Acrylics) are studied in the dose range of $10^{1}-10^{6} \mathrm{~Gy}$. It is observed that due to gamma exposure the bulk and track-etch rates of the detector increases. This increase in both etchrates is more pronounced in post gamma exposed PADC detectors. The etchrate ratio $(\mathrm{S})$ for both pre and post-gamma exposed detectors decreases with increasing etching temperature at the dose of $10^{6} \mathrm{~Gy}$. At a higher etching temperature of $70^{\circ} \mathrm{C}$, the etch rates ratio becomes almost equal for post gamma exposed detector. Etching efficiency of the detector is found to be much higher when exposed to gamma radiation. However it is observed that at the etching temperature of $70^{\circ} \mathrm{C}$, etching efficiency for both pre and post-gamma exposed samples tends to become almost equal to the pristine one.
\end{abstract}

Key Words: PADC-American Acrylics, Gamma Dose, Etch-Rates, Pre-Gamma, Post-Gamma.

\section{Introduction}

Studies on Solid State Nuclear Track Detectors (SSNTDs) are becoming very popular in recent years because of the wide applications these detectors have in the fields of science and technology. ${ }^{1-6}$ The applications of these detectors are dependent on the type of external radiation they are exposed to, and it is now an established fact that properties of track detectors are modified to different extents depending on the type of radiations they are exposed to. SSNTDs are greatly influenced by gamma radiation and in this regard a lot of work on various track detectors has been reported by several authors. ${ }^{7-18}$ It has been mostly observed that etch-rates increases upon gamma exposure. This increase in etch rates is attributed to scissioning of the molecular chains of the track detectors, which reduces their average molecular weight. For example, we have earlier reported that for PADC detectors ${ }^{10}$ the scissioning of polyallyl chains with diethyleneglycol takes place at the dose of $10^{6} \mathrm{~Gy}$. However it has been observed that most of the work on gamma effect on track detectors is 
restricted to limited gamma doses. In this particular work, effect of gamma dose as high as $10^{6}$ Gy has been studied. The change in track properties like etch-rates, etching efficiency, etch-rate ratio etc. of the detector are studied at different etching temperature. Further the results are compared for both pre and post-gamma exposed detectors.

\section{Experimental}

The PADC detector used in this study is PADC-American Acrylics manufactured by American Acrylics, USA. The thickness of this detector is around $650 \mu \mathrm{m}$. For this study, two sets of samples of sizes $2 \times 2 \mathrm{~cm}^{2}$ (seven numbers for each set) of PADC detectors were prepared from the commercially available sheets. One set of samples was first exposed at normal incidence to alpha and fission fragments from a ${ }^{252} \mathrm{Cf}$ source (having a half-life of 2.65 years and activities $5.7 \times 10^{3}$ fission/minute and $1.84 \times 10^{5}$ alpha particles/minute). The pre-exposed samples along with the unexposed second set of samples were then irradiated with various doses of gamma radiation in the dose range of $10^{1}$ to $10^{6} \mathrm{~Gy}$. The exposure was made from a ${ }^{60} \mathrm{Co}$ gamma source having a dose rate of $3 \mathrm{kGy} / \mathrm{h}$. Subsequent to the gamma exposure, the second set was exposed to the ${ }^{252} \mathrm{Cf}$ source for alpha and fission fragment detection. The first and the second sets are referred to as the post-gamma and pregamma sets respectively, in this study. After the fission fragments, alpha and gamma exposure, the detectors were etched in $6 \mathrm{~N} \mathrm{NaOH}$ solution at four different temperatures i.e., at $55^{\circ} \mathrm{C}, 60^{\circ} \mathrm{C}, 65^{\circ} \mathrm{C}$ and $70^{\circ} \mathrm{C}$. The track diameters of the incident fission fragments and alpha particles were measured using a Leitz Optical Microscope. The bulk-etch rate $\left(\mathrm{V}_{\mathrm{G}}\right)$ and track-etch rate $\left(\mathrm{V}_{\mathrm{T}}\right)$, were determined from the following expressions ${ }^{7}$.

$$
\mathrm{V}_{\mathrm{G}}=\mathrm{D}_{\mathrm{ff}} / 2 \mathrm{t}, \quad \mathrm{V}_{\mathrm{T}}=\mathrm{V} \times \mathrm{V}_{\mathrm{G}}
$$

where $\mathrm{V}=1+\mathrm{x}^{2} / 1-\mathrm{x}^{2}$ with $\mathrm{x}=\mathrm{D}_{\mathrm{ff}} / \mathrm{D}_{\alpha}$, where $\mathrm{D}_{\mathrm{ff}}$ is the diameter of fission track and $\mathrm{D}_{\alpha}$ is the diameter of the alpha track. Other track properties like etching efficiency, etch-rate ratio were determined from the equations given below:

$$
\text { Etching efficiency } \eta(\%)=\left(1-\mathrm{V}_{\mathrm{G}} / \mathrm{V}_{\mathrm{T}}\right) \times 100, \text { Etch-rate ratio } \mathrm{S}=\mathrm{V}_{\mathrm{T}} / \mathrm{V}_{\mathrm{G}}{ }^{7}
$$

\section{Results and Discussion}

The bulk and track- etch rates $\left(\mathrm{V}_{\mathrm{G}} \& \mathrm{~V}_{\mathrm{T}}\right)$ for both pre and post gamma exposed PADC detectors are given in Tables 1-4. It is observed that for both cases, etch-rates increase due to gamma exposure and this increase starts at a dose higher than $10^{4} \mathrm{~Gy}$. For example an increase of around 22 fold and 26.42 fold takes place in both $\mathrm{V}_{\mathrm{G}}$ and $\mathrm{V}_{\mathrm{T}}$ for pre-gamma exposed detector and also an increase of 23.28 fold and 26.51 fold takes place in $\mathrm{V}_{\mathrm{G}}$ and $\mathrm{V}_{\mathrm{T}}$ for post-gamma exposed detectors when etched at $55^{\circ} \mathrm{C}$. Since the etch-rate generally increases due to scissioning of the molecular chain, it may be possible that scissioning of the molecular chain starts at a dose of $10^{4} \mathrm{~Gy}$. The possible route for gamma-induced scission of PADC chain is by the cleavage of polyallyl linkage with diethylene glycol, as has been reported earlier. ${ }^{10}$ With increasing gamma dose, the intensity of chain scissioning phenomena probably increases. Interestingly it is observed that at the dose of $10^{6} \mathrm{~Gy}$, the post-gamma irradiated detectors have almost the same etch-rate values as pre-gamma irradiated detectors, which is not the case for other types of PADC detectors we studied earlier. $^{11-12}$ 
Table 1. Bulk-Etch rate $\left(\mathrm{V}_{\mathrm{G}}\right)$ in $\mu \mathrm{m} / \mathrm{h}$ for pre-gamma exposed PADC -American Acrylics.

\begin{tabular}{|l|l|l|l|l|l|l|l|}
\hline Temp ${ }^{0} \mathrm{C}$ & No Dose & $10^{1} \mathrm{~Gy}$ & $10^{2} \mathrm{~Gy}$ & $10^{3} \mathrm{~Gy}$ & $10^{4} \mathrm{~Gy}$ & $10^{5} \mathrm{~Gy}$ & $10^{6} \mathrm{~Gy}$ \\
\hline $55^{\circ} \mathrm{C}$ & $0.35 \pm 0.05$ & $0.34 \pm 0.05$ & $0.34 \pm 0.05$ & $0.38 \pm 0.05$ & $0.39 \pm 0.05$ & $0.47 \pm 0.05$ & $7.70 \pm 1.1$ \\
\hline $60^{\circ} \mathrm{C}$ & $0.59 \pm 0.06$ & $0.58 \pm 0.06$ & $0.57 \pm 0.06$ & $0.59 \pm 0.06$ & $0.73 \pm 0.06$ & $0.82 \pm 0.06$ & $11.48 \pm 1.2$ \\
\hline $65^{\circ} \mathrm{C}$ & $0.85 \pm 0.10$ & $0.87 \pm 0.10$ & $0.88 \pm 0.10$ & $0.89 \pm 0.10$ & $1.16 \pm 0.10$ & $1.22 \pm 0.10$ & $18.90 \pm 1.3$ \\
\hline $70^{\circ} \mathrm{C}$ & $1.15 \pm 0.11$ & $1.15 \pm 0.11$ & $1.15 \pm 0.11$ & $1.22 \pm 0.11$ & $1.19 \pm 0.11$ & $1.58 \pm 0.11$ & $26.95 \pm 1.8$ \\
\hline
\end{tabular}

Table 2. Track-Etch rate $\left(\mathrm{V}_{\mathrm{T}}\right)$ in $\mu \mathrm{m} / \mathrm{h}$ for pre-gamma exposed PADC -American Acrylics.

\begin{tabular}{|l|l|l|l|l|l|l|l|}
\hline Temp ${ }^{0} \mathrm{C}$ & No Dose & $10^{1} \mathrm{~Gy}$ & $10^{2} \mathrm{~Gy}$ & $10^{3} \mathrm{~Gy}$ & $10^{4} \mathrm{~Gy}$ & $10^{5} \mathrm{~Gy}$ & $10^{6} \mathrm{~Gy}$ \\
\hline $55^{0} \mathrm{C}$ & $0.54 \pm 0.05$ & $0.53 \pm 0.05$ & $0.52 \pm 0.05$ & $0.57 \pm 0.05$ & $0.55 \pm 0.05$ & $0.69 \pm 0.05$ & $14.27 \pm 1.1$ \\
\hline $60^{0} \mathrm{C}$ & $0.87 \pm 0.06$ & $0.89 \pm 0.06$ & $0.88 \pm 0.06$ & $0.91 \pm 0.06$ & $1.05 \pm 0.06$ & $1.26 \pm 0.06$ & $19.95 \pm 1.2$ \\
\hline $65^{0} \mathrm{C}$ & $1.11 \pm 0.10$ & $1.15 \pm 0.10$ & $1.07 \pm 0.10$ & $1.09 \pm 0.10$ & $1.51 \pm 0.10$ & $1.73 \pm 0.10$ & $29.29 \pm 1.3$ \\
\hline $70^{0} \mathrm{C}$ & $1.86 \pm 0.11$ & $1.86 \pm 0.11$ & $1.96 \pm 0.11$ & $1.95 \pm 0.11$ & $2.17 \pm 0.11$ & $2.49 \pm 0.11$ & $46.54 \pm 1.8$ \\
\hline
\end{tabular}

Table 3. Bulk-Etch rate $\left(\mathrm{V}_{\mathrm{G}}\right)$ in $\mu \mathrm{m} / \mathrm{h}$ for post-gamma exposed PADC -American Acrylics.

\begin{tabular}{|l|l|l|l|l|l|l|l|}
\hline Temp ${ }^{0} \mathrm{C}$ & No Dose & $10^{1} \mathrm{~Gy}$ & $10^{2} \mathrm{~Gy}$ & $10^{3} \mathrm{~Gy}$ & $10^{4} \mathrm{~Gy}$ & $10^{5} \mathrm{~Gy}$ & $10^{6} \mathrm{~Gy}$ \\
\hline $55^{0} \mathrm{C}$ & $0.35 \pm 0.05$ & $0.35 \pm 0.05$ & $0.36 \pm 0.05$ & $0.38 \pm 0.05$ & $0.44 \pm 0.05$ & $0.50 \pm 0.05$ & $8.15 \pm 1.1$ \\
\hline $60^{0} \mathrm{C}$ & $0.59 \pm 0.06$ & $0.59 \pm 0.06$ & $0.59 \pm 0.06$ & $0.60 \pm 0.06$ & $0.82 \pm 0.06$ & $0.90 \pm 0.06$ & $12.58 \pm 1.2$ \\
\hline $65^{\circ} \mathrm{C}$ & $0.85 \pm 0.10$ & $0.86 \pm 0.10$ & $0.86 \pm 0.10$ & $0.90 \pm 0.10$ & $1.21 \pm 0.10$ & $1.35 \pm 0.10$ & $21.27 \pm 1.3$ \\
\hline $70^{0} \mathrm{C}$ & $1.15 \pm 0.11$ & $1.14 \pm 0.11$ & $1.15 \pm 0.11$ & $1.15 \pm 0.11$ & $1.47 \pm 0.11$ & $1.66 \pm 0.11$ & $28.04 \pm 1.8$ \\
\hline
\end{tabular}

Table 4. Track-Etch rate $\left(\mathrm{V}_{\mathrm{T}}\right)$ in $\mu \mathrm{m} / \mathrm{h}$ for post-gamma exposed PADC -American Acrylics.

\begin{tabular}{|c|c|c|c|c|c|c|c|}
\hline $\mathrm{Temp}^{0} \mathrm{C}$ & No Dose & $10^{1} \mathrm{~Gy}$ & $10^{2} \mathrm{~Gy}$ & $10^{3} \mathrm{~Gy}$ & $10^{4} \mathrm{~Gy}$ & $10^{5} \mathrm{~Gy}$ & $10^{6} \mathrm{~Gy}$ \\
\hline $55^{0} \mathrm{C}$ & 0.341 & $0.54 \pm 0.05$ & 0.54 & $0.55=$ & $0.72 \pm 0.05$ & $0.76=$ & $4.32 \pm 1.1$ \\
\hline $60^{\circ} \mathrm{C}$ & $0.87 \pm 0.06$ & $0.90 \pm 0.06$ & $0.91=$ & $0.89 \pm 0.06$ & $1.22 \pm 0.06$ & $1.36 \pm 0.06$ & $20.18 \pm 1.2$ \\
\hline $65^{0} \mathrm{C}$ & 11 & $12 \pm 0.10$ & .12 & $1.23 \pm 0$ & $1.55=$ & 1.87 & 29.45 \\
\hline $70^{\circ} \mathrm{C}$ & $1.86 \pm 0.11$ & $85 \pm 0.11$ & $1.99 \pm 0.11$ & $1.99 \pm 0.11$ & $2.77 \pm 0.11$ & $2.90 \pm 0.11$ & $46.70 \pm 1.8$ \\
\hline
\end{tabular}

Etch-rate ratio values for the detector are found to increase at the highest dose of $10^{6}$ Gy. At an etching temperature of $55^{\circ} \mathrm{C}$, a increase of approximately $20 \%$ and $14 \%$ in etchrates for both pre-gamma and post-gamma exposed detectors respectively are observed at the highest dose. But at higher etching temperature like $60^{\circ} \mathrm{C}, 65^{\circ} \mathrm{C}$ or $70^{\circ} \mathrm{C}$, the etch-rate ratio is found to decrease with increasing etching temperature. For example for pre-gamma exposed detectors, the etch-rate is found to be $20.12 \%, 17.68 \%, 18.46 \%, 6.83 \%$ respectively at etching temperature of $55^{\circ} \mathrm{C}, 60^{\circ} \mathrm{C}, 65^{\circ} \mathrm{C}$ and $70^{\circ} \mathrm{C}$ and for post-gamma exposed detectors the etch-rate ratio is found to be $13.6 \%, 8.84 \%, 6.15 \%$ and $3.10 \%$ respectively at the highest dose. These results indicate that even though the etch-rate increases due to gamma exposure, the etching temperature has significant effect on the etch-rate ratio. The gradual decrease in the etch-rate ratio with increasing etching temperature at the highest dose indicates that at higher temperature, the rate of attack of the solvent along the surface is very fast as compared to the attack along the track. 
Table 5. Etch-Rate ratio for pre-gamma exposed PADC -American Acrylics.

\begin{tabular}{|l|l|l|l|l|l|l|l|}
\hline Temp ${ }^{0} \mathrm{C}$ & No Dose & $10^{1} \mathrm{~Gy}$ & $10^{2} \mathrm{~Gy}$ & $10^{3} \mathrm{~Gy}$ & $10^{4} \mathrm{~Gy}$ & $10^{5} \mathrm{~Gy}$ & $10^{6} \mathrm{~Gy}$ \\
\hline $55^{0} \mathrm{C}$ & 1.54 & 1.55 & 1.52 & 1.50 & 1.41 & 1.46 & 1.85 \\
\hline $60^{0} \mathrm{C}$ & 1.47 & 1.53 & 1.54 & 1.54 & 1.43 & 1.53 & 1.73 \\
\hline $65^{0} \mathrm{C}$ & 1.30 & 1.32 & 1.21 & 1.22 & 1.30 & 1.41 & 1.54 \\
\hline $70^{\circ} \mathrm{C}$ & 1.61 & 1.61 & 1.70 & 1.59 & 1.82 & 1.57 & 1.72 \\
\hline
\end{tabular}

Table 6. Etch-Rate ratio for post-gamma exposed PADC-American Acrylics.

\begin{tabular}{|l|l|l|l|l|l|l|l|}
\hline Temp ${ }^{0} \mathrm{C}$ & No Dose & $10^{1} \mathrm{~Gy}$ & $10^{2} \mathrm{~Gy}$ & $10^{3} \mathrm{~Gy}$ & $10^{4} \mathrm{~Gy}$ & $10^{5} \mathrm{~Gy}$ & $10^{6} \mathrm{~Gy}$ \\
\hline $55^{0} \mathrm{C}$ & 1.54 & 1.54 & 1.50 & 1.44 & 1.63 & 1.52 & 1.75 \\
\hline $60^{0} \mathrm{C}$ & 1.47 & 1.52 & 1.54 & 1.48 & 1.48 & 1.51 & 1.60 \\
\hline $65^{0} \mathrm{C}$ & 1.30 & 1.30 & 1.30 & 1.36 & 1.28 & 1.38 & 1.38 \\
\hline $70^{\circ} \mathrm{C}$ & 1.61 & 1.62 & 1.73 & 1.73 & 1.88 & 1.74 & 1.66 \\
\hline
\end{tabular}

The etching efficiencies (\%) of the detectors for both pre and post gamma exposed detectors are given in Figure 1 and Figure 2. It is observed that with increasing gamma dose, the etching efficiency increases at the highest dose. At all etching temperatures it is observed that with increasing gamma dose, there is a slight increase in etching efficiency initially followed by decrease and finally a significant increase at the highest dose of $10^{6} \mathrm{~Gy}$. However it is worth observing that there is a tendency that the etching efficiency values (\%) become almost equal at the dose of $10^{6} \mathrm{~Gy}$ when etched at $70^{\circ} \mathrm{C}$. This observation indicates that there is a likelihood that at the dose of $10^{6} \mathrm{~Gy}$, the etching temperatures probably lose their significance.

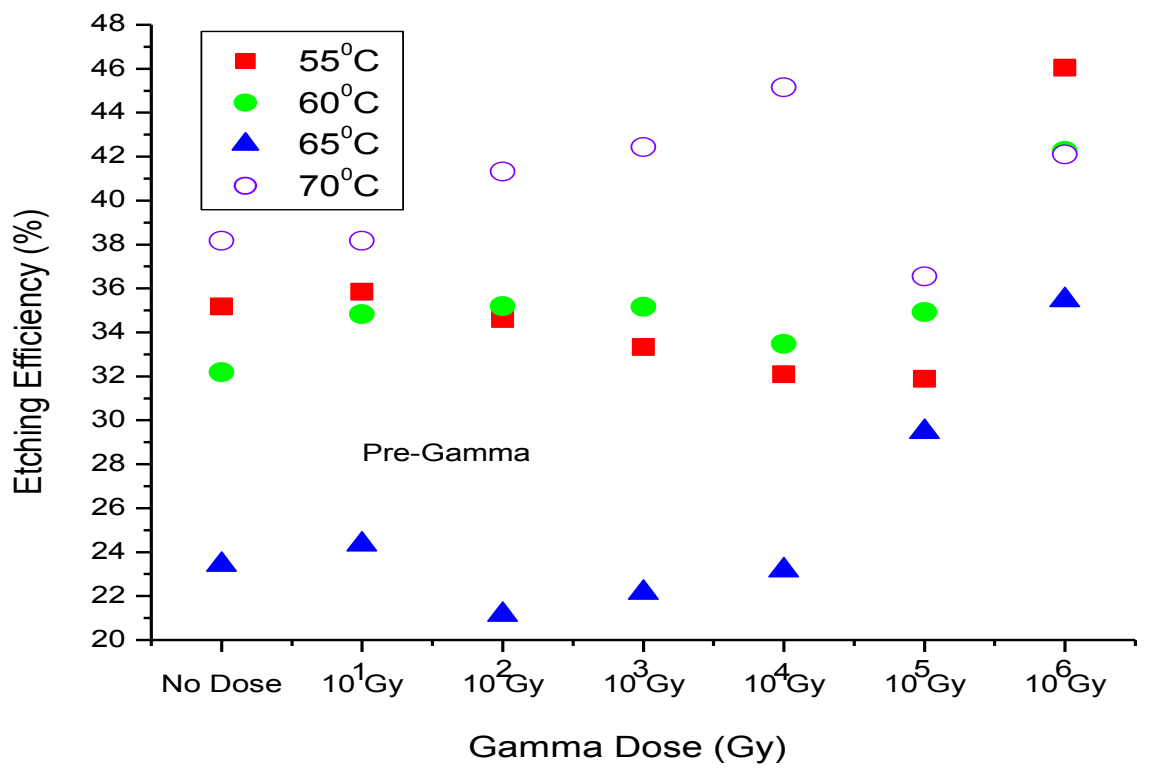

Figure 1. Plot of gamma dose vs. etching efficiency for pre -gamma radiation exposed PADC (American Acrylics) detectors at different etching temperatures. 


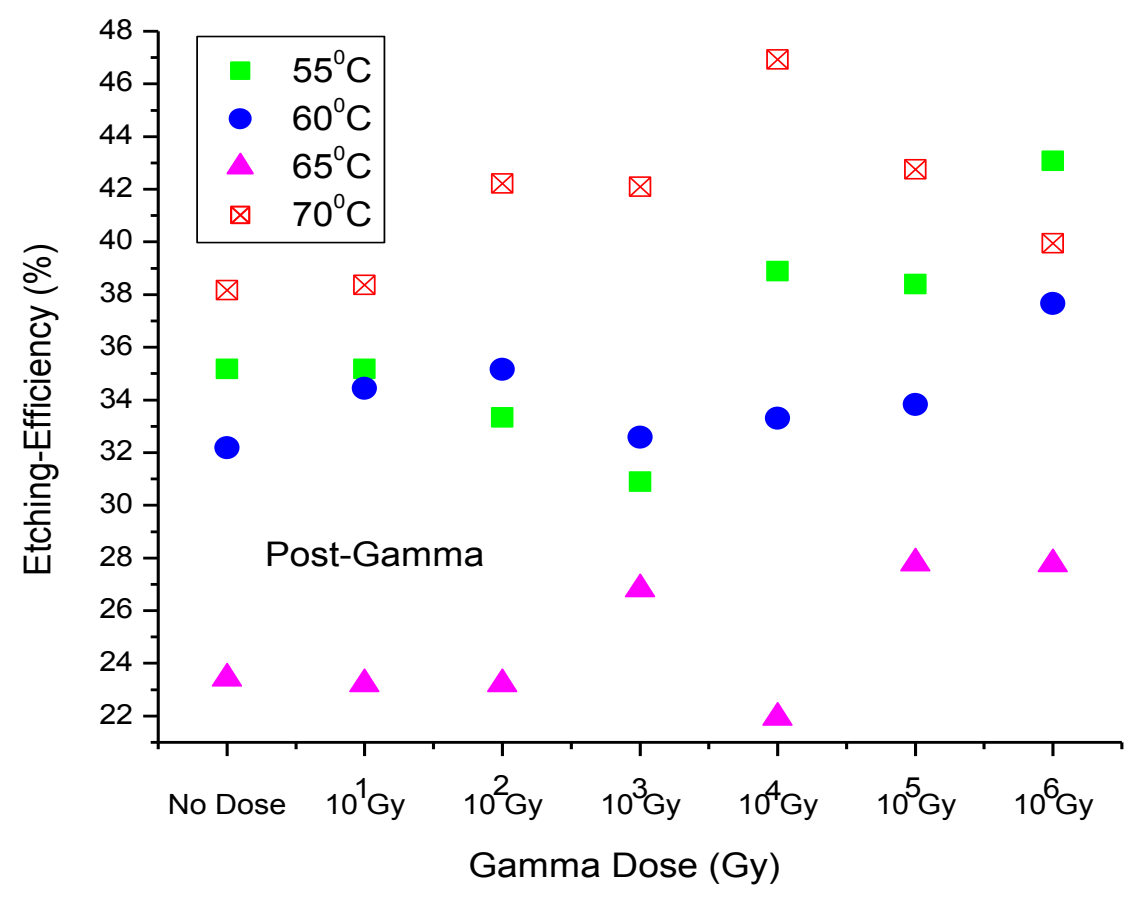

Figure 2. Plot of gamma dose vs. critical etching efficiency for post -gamma radiation exposed PADC (American Acrylics) detectors at different etching temperatures.

\section{Conclusions}

On the basis of the present study, it is concluded that:

1. Due to gamma exposure, both the bulk and track-etch rates of PADC-American Acrylics increases and the increase is visible above the dose of $10^{4} \mathrm{~Gy}$.

2. For both pre and post gamma exposed detectors, the etch rates increases at the higher doses.

3. At the highest dose of gamma radiation, i.e., at $10^{6}$ Gy radiation, etch-rate ratio (S) values for the detectors are found to increase.

4. With increasing etching temperature, the etch-rate ratio is found to decrease. The gradual decrease in the etch-rate ratio with increasing etching temperature at the highest does indicates that at the higher temperature, the rate of attack of the solvent along the surface is very fast as compared to the attack along the track.

5. The etching efficiencies (\%) of the detectors reveal that with increasing gamma dose, the efficiency increases at the higher doses.

\section{Acknowledgement}

The author is grateful to Professor K. K. Dwivedi, for having introduced to this area of research. Also grateful to Prof. V. G. Dedgaonkar, Pune University for gamma exposure of the detectors. 


\section{References}

1. Fleischer R L, Price P B, Walker R M and Leakley L S B, Science, 1965, 148, 72-74.

2. Spohr R, Daur U and Busch L C, Biomedizinische Technik, 1981, 26, 167-169.

3. Fischer B E and Spohr R, Rev. Mod. Phys., 1983, 55, 907-948.

4. Lee E H, Lewis M B, Blan B J and Mansur L K, J. Mat. Res., 1991, 6, 610-628.

5. Fink D, Fundamentals of Ion-irradiated Polymers, 2004. (Springer Series in

6. Materials Science)

7. Fink D, Alegaonkar P S, Petrov A V, Wilhelm M, Szimkowiak P, Behar M, Sinha D Fahrner W R, Hoppe K and Chadderton L T, Nucl. Instrum. Meth.B, 2005, 236, 11-20.

8. Shweikani R, Durrani S A and Tsuruta T, Nucl. Tracks Radiat. Meas. 1993, 22 153156.

9. Komaki Y, Ishikawa N and Sakurai T, Radiat. Meas. 1995, 24, 193-196.

10. Abu-Jarad F, Hala A M, Farhat M and Islam M, Radiat. Meas., 1997, 28 , 111-114.

11. Sinha D and Dwivedi K K, Radiat. Phys. Chem. 1998, 53, 99-105.

12. Sinha D, Mishra R, Tripathy S P and Dwivedi K K, Radiat. Meas., 2001, 33, 139-143.

13. Sinha D, Swu T, Tripathy S P, Mishra R and Dwivedi K K, Radiat. Meas. 2003, 36, $229-231$.

14. Singh S and Prasher S, Nucl. Instrum. Meth B., 2004, 222, 518-524.

15. Agarwal C, Kalsi P C, Ramaswami A, Rad. Eff. Def. Sol., 2006, $161131-133$.

16. Prasher N S and Singh S, Radiat. Meas., 2007, 42, 135-137.

17. Zaki M F and Seddik U, 2007, 162, $449-453$.

18. Sinha D, Rad. Eff. Def. Sol., 2009, 164, 604-610. 


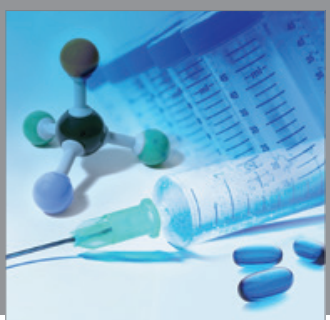

International Journal of

Medicinal Chemistry

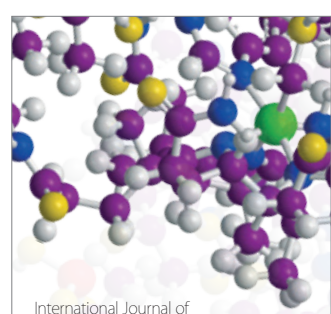

Carbohydrate Chemistry

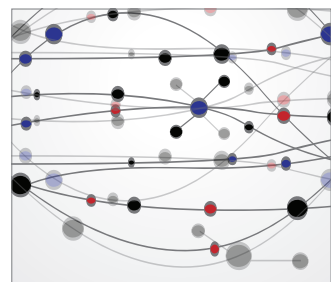

The Scientific World Journal
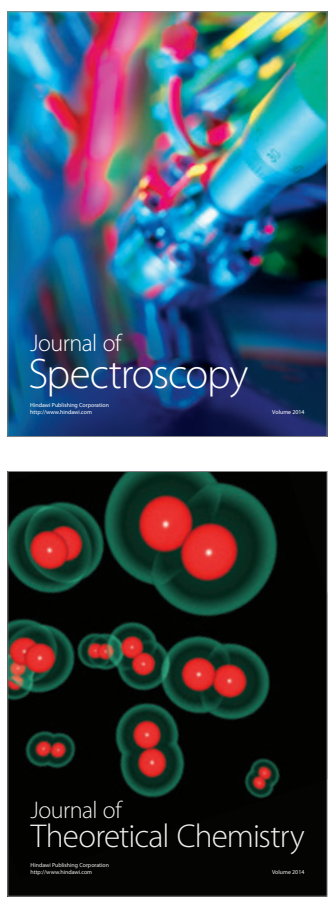
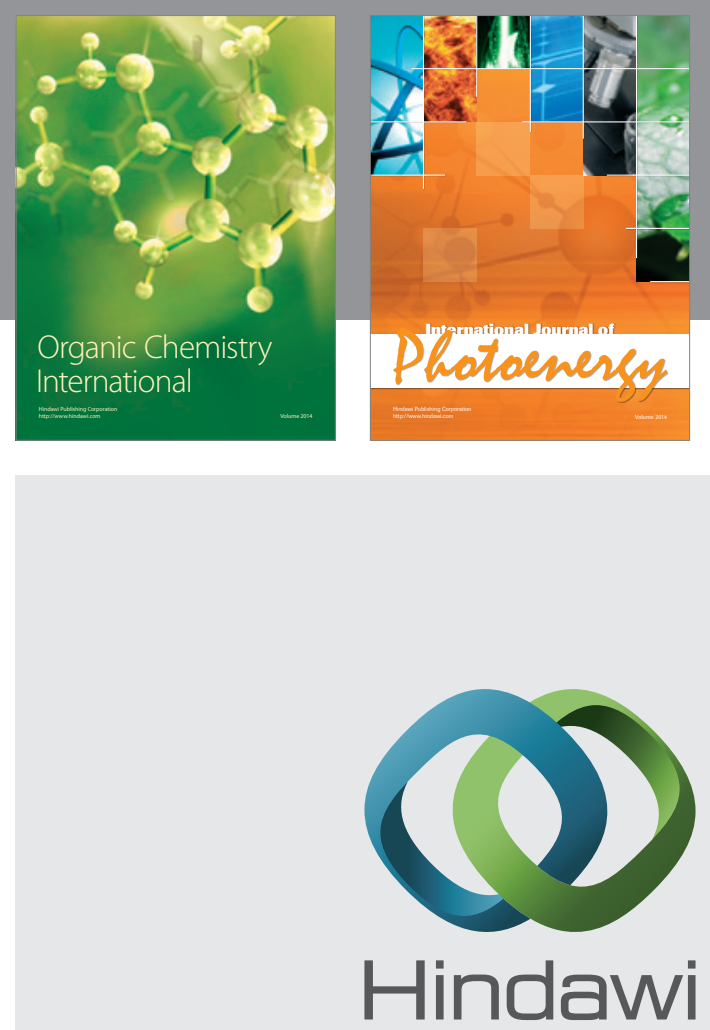

Submit your manuscripts at

http://www.hindawi.com
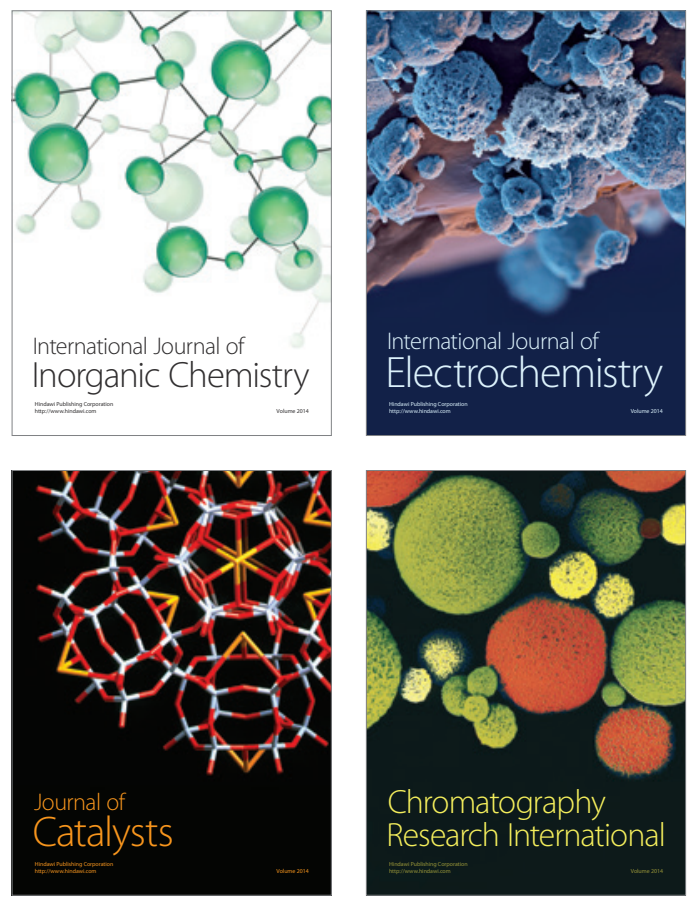
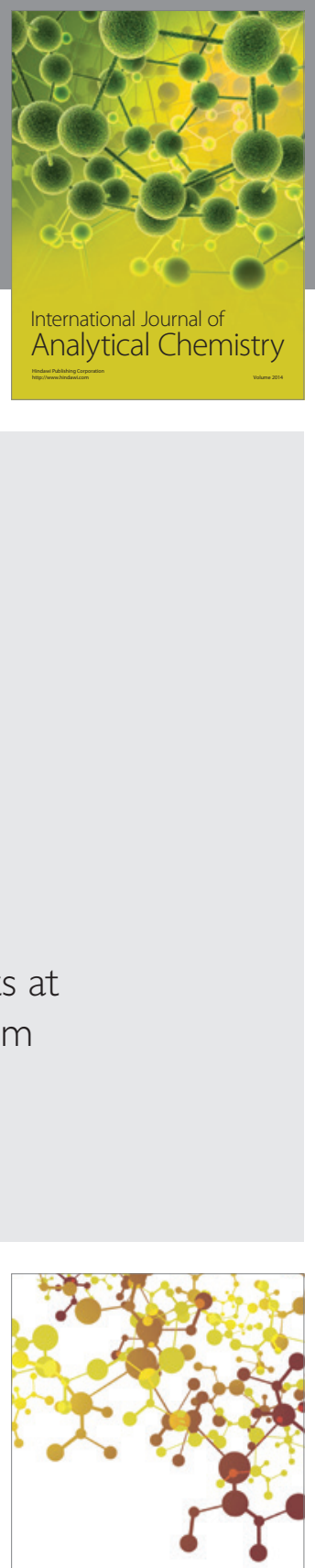

Journal of

Applied Chemistry
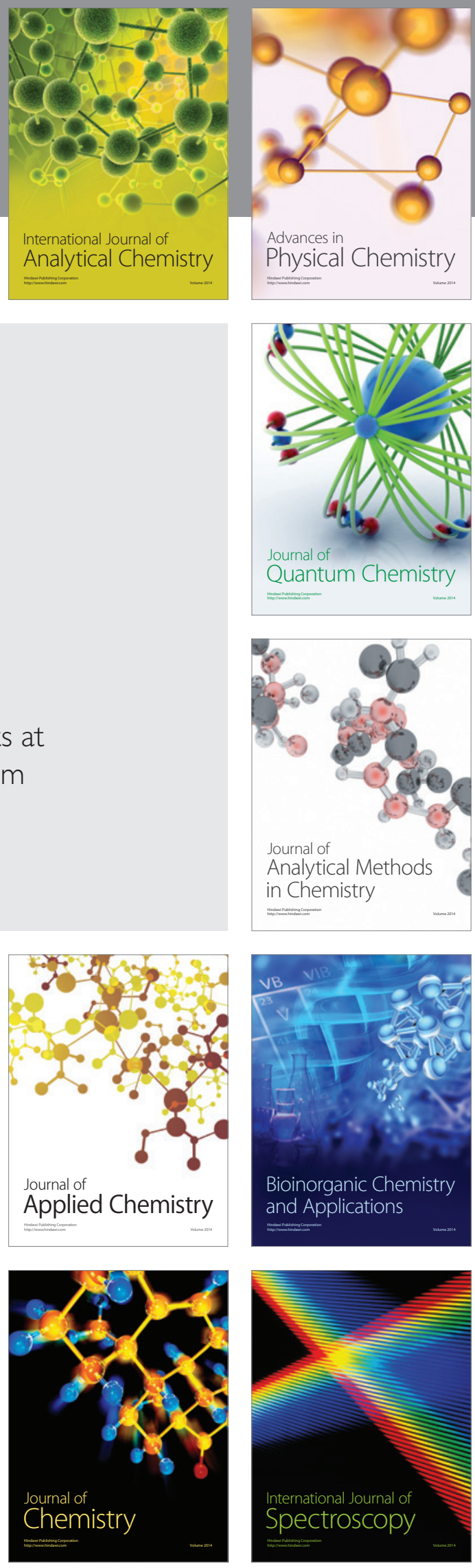